\title{
KONSENTRASI PACLOBUTRAZOL DAN PERTUMBUHAN TINGGI BIBIT CENGKEH (Syzygium aromaticum (L.) Merryl \& Perry)
}

\section{THE CONCENTRATION OF PACLOBUTRAZOL ON GROWTH OF SEEDLING CLOVES HEIGHT (Syzygium aromaticum (L.) Merryl \& Perry)}

\author{
Semuel D. Runtunuwu ${ }^{1 *}$, Rinny Mamarimbing ${ }^{1}$, Pemmy Tumewu dan Tommy Sondakh ${ }^{2}$ \\ 'Lab. IImu Tanaman Fak. Pertanian Unsrat, 2Jurusan IImu Tanah Fak. Pertanian Unsrat \\ *alamat untuk korespondensi : semueldr@gmail.com.
}

\begin{abstract}
The purpose of this research was to study the effect of the concentration of growth inhibitor Paclobutrazol (Pbz) against the high growth of clove seedlings (Syzygium aromaticum (L.) Merryl \& Perry) and get Pbz concentrations that can produce seed cloves in a relatively short (dwarf). The results showed that spraying Paclobutrazol (Pbz) with 25-100 ppm affect height growth of clove seedlings. Pbz the higher concentration applications, the shorter the length of apical segments produced shoots. In other words, the higher the concentration $\mathrm{Pbz}$, the higher the emphasis on high growth of clove seedlings. Pbz emphasis on high growth of clove seedlings varied from the lowest, ie. $3.79 \%$ (25 ppm) up to the highest, ie $69.85 \%$ (100 ppm). Based on the comparison of height increment of plants sprayed with Paclobutrazol, the dose applications can be used to get the seed cloves that dwarf is a concentration of 50 to $100 \mathrm{ppm}$.
\end{abstract}

Key Words : Paclobutrazol, Gibberellin, Clove, Dwarfism

\begin{abstract}
ABSTRAK
Tujuan penelitian ini adalah mempelajari pengaruh konsentrasi zat penghambat tumbuh paclobutrazol (Pbz) terhadap pertumbuhan tinggi bibit cengkeh (Syzygium aromaticum (L.) Merryl \& Perry) dan mendapatkan konsentrasi $\mathrm{Pbz}$ yang dapat menghasilkan bibit cengkeh yang relatif pendek (kerdil). Hasil penelitian menunjukan bahwa penyemprotan paclobutrazol (Pbz) dengan 25 - 100 ppm mempengaruhi pertumbuhan tinggi bibit cengkeh. Makin tinggi konsentrasi aplikasi Pbz, makin pendek panjang ruas tunas apikal yang dihasilkan. Dengan kata lain, makin tinggi konsentrasi Pbz, makin tinggi pula penekanan terhadap pertumbuhan tinggi bibit cengkeh. Penekanan $\mathrm{Pbz}$ terhadap pertumbuhan tinggi bibit cengkeh bervariasi dari terendah, yaitu 3,79 \% (25 ppm) sampai dengan tertinggi, yaitu $69,85 \%$ (100 ppm). Berdasarkan perbandingan pertambahan tinggi tanaman, maka dosis aplikasi yang dapat digunakan untuk mendapatkan bibit cengkeh yang kerdil adalah konsentrasi 50 sampai dengan $100 \mathrm{ppm}$.

Kata kunci : Paclobutrazol, Gibberellin, Clove, Dwarfism
\end{abstract}

Eugenia Volume 17 No. 2 Agustus 2011 


\section{PENDAHULUAN}

Tanaman cengkeh (Syzygium aromaticum (L.) Merryl \& Perry atau Eugenia aromatica (L.) Baill) adalah salah satu tanaman tahunan yang dapat tumbuh sampai usia puluhan tahun bahkan ratusan tahun dan tanaman dapat tumbuh mencapai 20 meter (Guzman and Siemonsma, 1999). Hasil tanaman ini berupa bunga cengkeh terletak pada bagian unjung tunas. Sehingga untuk memetik bunga, petani harus menggunakan tangga bambu yang disandarkan pada tajuk/kanopi tanaman. Akibatnya dengan makin bertambah umur tanaman, makin bertambah pula tinggi tanamannya. Hal ini menyebabkan pada tanamantanaman cengkeh yang sudah berumur di atas 20an tahun, bunga yang ada pada tajuk bagian atas akan sulit untuk dipetik karena tanamannya sudah tinggi (bisa lebih dari $15 \mathrm{~m}$ ).

Kesulitan memetik bunga cengkeh pada tajuk bagian atas tajuk, bukan saja terletak pada tangganya yang tinggi, sehingga sulit mendapatkan bahan untuk membuat tangga (bambu) yang panjangnya sekitar $15 \mathrm{~m}$. Disamping itu, dengan semakin tingginya tangga akan semakin sulit memindahkan tangga dari satu pohon ke pohon lainnya apalagi pada lahan-lahan yang curam seperti di daerah Kombi dan Tombariri. Tapi juga dengan semakin tingginya tangga maka resiko kecelakaan pada saat memetik semakin besar, terutama saat musim pemetikan pada saat itu angin bertiup cukup kencang, yang bisa merobohkan tangga.

Untuk mengatasi masalah tersebut, perlu dikaji aplikasi zat pengatur tumbuh (ZPT), dalam hal ini paclobutrazol ( $\mathrm{Pbz}$ ) pada tanaman bibit untuk menghasilkan tanaman cengkeh yang kerdil. Paclobutrazol tergolong zat penghambat tumbuh (growth retardant) (Chaney, 2004), yang dapat menghambat/menekan pertumbuhan tinggi tanaman, meningkatkan warna hijau daun, meningkatkan produksi tanpa menyebabkan pertumbuhan abnormal (Christov et.al., 1995). Pada tanaman kelapa sawit, pengaruh paclobutrazol terhadap tinggi tanaman mulai nampak pada bulan kedua sesudah aplikasi (Carvajal, Alvarado, Sterling and Rodríguez, 1998). Hasil penelitian yang sudah dilakukan menunjukkan bahwa paclobutrazol, baik langsung disemprot melalui daun maupun disiram lewat tanah dapat menekan pertumbuhan tinggi tanaman padi (Mamarimbing, 2003a,b).

Tujuan penelitian ini adalah mempelajari pengaruh konsentrasi paclobutrazol terhadap pertumbuhan tinggi bibit cengkeh dan mendapatkan konsentrasi paclobutrazol yang dapat menghasilkan bibit cengkeh dengan ruasruas batang utama yang pendek (kerdil).

\section{METODE PENELITIAN}

Penelitian dilakukan selama lima bulan, yaitu mulai bulan November 2010 sampai dengan bulan Maret 2011 di Desa Talikuran Sonder, Kabupaten Minahasa.

Tanaman yang diteliti adalah 375 bibit cengkeh berumur sekitar 6 bulan, yang pertumbuhannya relatif seragam. Bibit cengkeh tersebut diseleksi bibit-bibit yang memiliki pertumbuhan cepat dari sekitar 100 ribu bibit cengkeh, yang disumbangkan PT. HM. Sampoerna Tbk. kepada Pemerintah Kabupaten Minahasa. Bebih cengkeh langsung dikecambahkan di polybag hitam khusus untuk bibit cengkeh.

Penelitian dilaksanakan menggunakan Rancangan acak kelompok (RAK) dengan perlakuan lima konsentrasi paclobutrazol. Konsentrasi paclobutrazol yang diteliti adalah: 1) 0 ppm (kontrol), 2) 25 ppm, 3) 50 ppm, 4) 75 ppm, dan 5) 100 ppm. Setiap perlakuan diulang sebanyak 3 (tiga) kali dan setiap ulangan terdiri dari 25 tanaman. Penempatan perlakuan di lapangan adalah sebagai berikut:

\begin{tabular}{|c|c|c|c|c|c|}
\hline Pbz 100-1 & $\mathrm{Pbz} 75-1$ & Pbz 25-1 & $\mathrm{Pbz}$ 50-1 & Pbz 0-1 & $\mathrm{T}$ \\
\hline Pbz 100-2 & $\mathrm{Pbz} 75-2$ & $\mathrm{Pbz} 25-2$ & $\mathrm{Pbz}$ 50-2 & $\mathrm{Pbz} 0-2$ & \\
\hline Pbz 100-3 & Pbz 75-2 & Pbz 25-3 & Pbz 50-3 & $\mathrm{Pbz}$ 0-3 & B \\
\hline
\end{tabular}

Keterangan: $\mathrm{Pbz}=$ Paclobutrazol, $0-100=$ Konsentrasi Pbz, $1-3=$ Ulangan, $\mathrm{T}=$ Timur, dan $\mathrm{B}=$ Barat. 
Kemudian untuk mendorong pertumbuhan tanaman yang baik, bibit dipupuk dengan pupuk majemuk NPK (Phonska), pupuk organik (Petroganik) dan pupuk pelengkap Plant Catalyst PC2006, dengan dosis sesuai dosis anjuran untuk bibit.

Parameter yang diamati adalah: 1) Panjang ruas tunas apikal yang terbentuk sesudah aplikasi paclobutrazol, 2) Pertambahan panjang ruas tunas apikal yang terbentuk, dan 3) Tinggi bibit cengkeh.

Pengamatan dilakukan sebanyak empat kali, yaitu setiap bulan sekali setelah aplikasi Pbz. Sebelum dilakukan penyemprotan $\mathrm{Pbz}$, tinggi bibit diamati terlebih dahulu untuk mendapatkan tinggi awal bibit. Data yang diperoleh dianalisis dengan analisis sidik ragam untuk menentukan apakah zat penghambat tumbuh paclobutrazol berpengaruh terhadap pertumbuhan tinggi bibit cengkeh, yaitu jika $F$ hitung > F tabel. Selanjutnya untuk membedakan pengaruh diantara perlakuan konsentrasi maka analisis dilanjutkan dengan uji Beda Nyata Terkecil (BNT).

\section{HASIL DAN PEMBAHASAN}

\section{Hasil Penelitian \\ Panjang Ruas Tunas Apikal}

Paclobutrazol (Pbz) mempengaruhi panjang ruas tunas apikal bibit cengkeh pada taraf $5 \%$. Panjang ruas tunas apikal bibit yang disemprot dengan $\mathrm{Pbz}$ berbeda nyata dibandingkan dengan bibit yang tidak disemprot, kecuali perlakuan 25 ppm tidak berbeda nyata. Rata-rata panjang ruas tunas apikal bibit cengkeh yang terbentuk sesudah aplikasi Pbz rata-rata lebih pendek dibandingkan dengan rata-rata panjang ruas tunas apikal bibit cengkeh kontrol (Tabel 1).

Tabel 1. Rata-rata Panjang Ruas Tunas Apikal yang Terbentuk Sesudah Aplikasi Paclobutrazol (Table 1. Average Length of Shoot apical Segments Formed After the Application of Paclobutrazol)

\begin{tabular}{|c|c|c|c|c|c|}
\hline \multirow{2}{*}{$\begin{array}{c}\text { Perlakuan } \\
\text { (ppm Pbz) }\end{array}$} & \multicolumn{4}{|c|}{ Panjang Ruas ke- } & \multirow{2}{*}{ Rata-rata } \\
\cline { 2 - 5 } & 1 & 2 & 3 & 4 & \\
\hline 0 & $4,80 \mathrm{bc}$ & $6,10 \mathrm{bc}$ & $5,57 \mathrm{~b}$ & $4,67 \mathrm{c}$ & 5,29 \\
\hline 25 & $4,30 \mathrm{bc}$ & $6,00 \mathrm{bc}$ & $5,53 \mathrm{~b}$ & $4,50 \mathrm{c}$ & 5,08 \\
\hline 50 & $3,03 \mathrm{ab}$ & $4,47 \mathrm{bc}$ & $5,40 \mathrm{~b}$ & $3,00 \mathrm{~b}$ & 3,98 \\
\hline 75 & $2,73 \mathrm{a}$ & $4,17 \mathrm{~b}$ & $2,60 \mathrm{a}$ & $2,33 \mathrm{~b}$ & 2,96 \\
\hline 100 & $1,45 \mathrm{a}$ & $1,73 \mathrm{a}$ & $1,30 \mathrm{a}$ & $1,50 \mathrm{a}$ & 1,41 \\
\hline BNT $(0,05)$ & 1,59 & 1,63 & 2,14 & 1,14 & - \\
\hline KK & 25,92 & 19,30 & 27,89 & 18,83 & - \\
\hline
\end{tabular}

Keterangan: ppm = part per million; $\mathrm{Pbz}=$ paclobutrazol; angka yang diikuti dengan notasi huruf berbeda, berbeda secara nyata, $\mathrm{KK}=$ Koefisien keragaman

Tabel 2. Pengaruh Paclobutrazol terhadap Pertambahan Tinggi Bibit Cengkeh (Table 2. The Effect of Paclobutrazol on Increasing of the Seedling Cloves Height)

\begin{tabular}{|c|c|c|c|c|c|}
\hline \multirow{3}{*}{$\begin{array}{l}\text { Perlakuan } \\
\text { (ppm Pbz) }\end{array}$} & \multicolumn{4}{|c|}{ Pengamatan ke- } & \multirow{3}{*}{ Penghambatan(\%) } \\
\hline & 1 & 2 & 3 & 4 & \\
\hline & \multicolumn{4}{|c|}{$\ldots \ldots \ldots . c m \ldots \ldots \ldots$} & \\
\hline 0 & $4,80 \mathrm{bc}$ & $10,90 \mathrm{c}$ & $16,47 e$ & $21,13 d$ & 0 \\
\hline 25 & $4,30 \mathrm{bc}$ & $10,30 \mathrm{c}$ & $15,83 d$ & $20,33 d$ & 3,79 \\
\hline 50 & $3,03 a b$ & $7,50 \mathrm{~b}$ & $12,90 \mathrm{c}$ & $15,90 \mathrm{c}$ & 24,75 \\
\hline 75 & $2,73 a$ & $6,90 b$ & $9,50 \mathrm{~b}$ & $11,83 b$ & 44,01 \\
\hline 100 & $1,45 a$ & $3,57 a$ & $4,87 a$ & $6,37 a$ & 69,85 \\
\hline BNT $(, 05)$ & 1,59 & 1,45 & 2,03 & 2,306 & - \\
\hline KK & 25,92 & 9,81 & 9,05 & 7,02 & - \\
\hline
\end{tabular}

Keterangan: ppm = part per million; $\mathrm{Pbz}=$ paclobutrazol; $\mathrm{KK}=$ Koefisien keragaman angka yang diikuti dengan notasi huruf berbeda, berbeda secara nyata 
Berdasarkan data pada Tabel 1, ternyata rata-rata panjang ruas tunas apikal bibit cengkeh kontrol, yaitu tanaman yang tidak disemprot dengan paclobutrazol (0 ppm Pbz) adalah $5,29 \mathrm{~cm}$, sedangkan rata-rata panjang ruas tunas apikal bibit yang disemprot dengan $\mathrm{Pbz}$ bervariasi dari yang terkecil, yaitu $1,41 \mathrm{~cm}$ (100 ppm) sampai dengan yang terbesar, yaitu $5,08 \mathrm{~cm}$ (25 ppm).

\section{Pertambahan Tinggi Bibit}

Paclobutrazol mempengaruhi pertambahan tinggi bibit tanaman cengkeh. Pertambahan tinggi bibit cengkeh yang disemprot dengan $\mathrm{Pbz}$ berbeda nyata pada taraf $5 \%$ dibandingkan dengan bibit yang tidak disemprot. Pertambahan tinggi selama empat bulan bibit cengkeh yang disemprot dengan $\mathrm{Pbz}$ lebih pendek dibandingkan dengan pertambahan tinggi bibit kontrol (Tabel 2).

Berdasarkan data pada Tabel 2, ternyata pertambahan tinggi bibit cengkeh yang tidak disemprot dengan Pbz (kontrol) adalah 21,13 cm, sedangkan pertambahan tinggi bibit yang disemprot dengan $\mathrm{Pbz}$ bervariasi dari paling kecil, yaitu 6,37 cm (100 ppm) sampai dengan paling besar, yaitu $20,33 \mathrm{~cm}$ (25 ppm).

\section{Pertumbuhan Tinggi Bibit}

Paclobutrazol mempengaruhi pertumbuhan tinggi bibit cengkeh pada taraf $5 \%$, kecuali perlakuan $25 \mathrm{ppm}$. Pengaruh $\mathrm{Pbz}$ terhadap pertumbuhan tinggi bibit mulai nyata pada pengamatan ketiga dan keempat sesudah aplikasi. Tinggi bibit cengkeh yang disemprot dengan $\mathrm{Pbz}$ lebih pendek dibandingkan dengan bibit yang tidak disemprot (kontrol) (Tabel 3).

Berdasarkan data pada Tabel 3, ternyata bibit cengkeh yang disemprot dengan paclobutrazol lebih pendek dibandingkan dengan bibit yang tidak disemprot. Tinggi bibit yang tidak disemprot dengan $\mathrm{Pbz}$ (kontrol) adalah $88,60 \mathrm{~cm}$ (paling tinggi), sedangkan tinggi bibit cengkeh yang disemprot $\mathrm{Pbz}$ bervariasi dari yang paling pendek, yaitu $74,23 \mathrm{~cm}$ (100 ppm) sampai dengan yang paling tinggi, yaitu $87,30 \mathrm{~cm}(25 \mathrm{ppm})$.

Tabel 3. Pengaruh Paclobutrazol terhadap Tinggi Bibit Cengkeh

(Table 3. The Effect of Paclobutrazol on the Seedling Cloves Height)

\begin{tabular}{|c|c|c|c|c|c|}
\hline \multirow{3}{*}{$\begin{array}{l}\text { Perlakuan } \\
\text { (ppm Pbz) }\end{array}$} & \multicolumn{5}{|c|}{ Pengamatan ke- } \\
\hline & 1 & 2 & 3 & 4 & 5 \\
\hline & \multicolumn{5}{|c|}{$\ldots \ldots \ldots c \mathrm{~cm} \ldots \ldots \ldots$} \\
\hline 0 & $67,47 a$ & $72,27 a$ & $78,37 a$ & $84,03 c$ & $88,60 \mathrm{c}$ \\
\hline 25 & $67,27 a$ & $71,57 a$ & $77,57 a$ & $82,80 \mathrm{c}$ & $87,30 \mathrm{c}$ \\
\hline 50 & $65,93 a$ & $68,97 a$ & $73,87 a$ & $79,07 b$ & $81,83 b$ \\
\hline 75 & $65,87 a$ & $68,60 \mathrm{a}$ & $73,43 a$ & $75,37 a b$ & $77,70 \mathrm{a}$ \\
\hline 100 & $68,30 a$ & $70,10 a$ & $71,83 a$ & $73,23 a$ & $74,23 a$ \\
\hline BNT $(, 05)$ & tn & tn & tn & 4,04 & 3,98 \\
\hline KK & 3,61 & 3,613 & 3,60 & 2,72 & 2,56 \\
\hline
\end{tabular}

Keterangan: $\mathrm{ppm}=$ part per million; $\mathrm{Pbz}=$ paclobutrazol; $\mathrm{KK}=$ koefisien keragaman. angka yang diikuti dengan notasi huruf berbeda, berbeda secara nyata; Pengamatan ke-1 adalah tinggi bibit cengkeh sebelum aplikasi Pbz. 


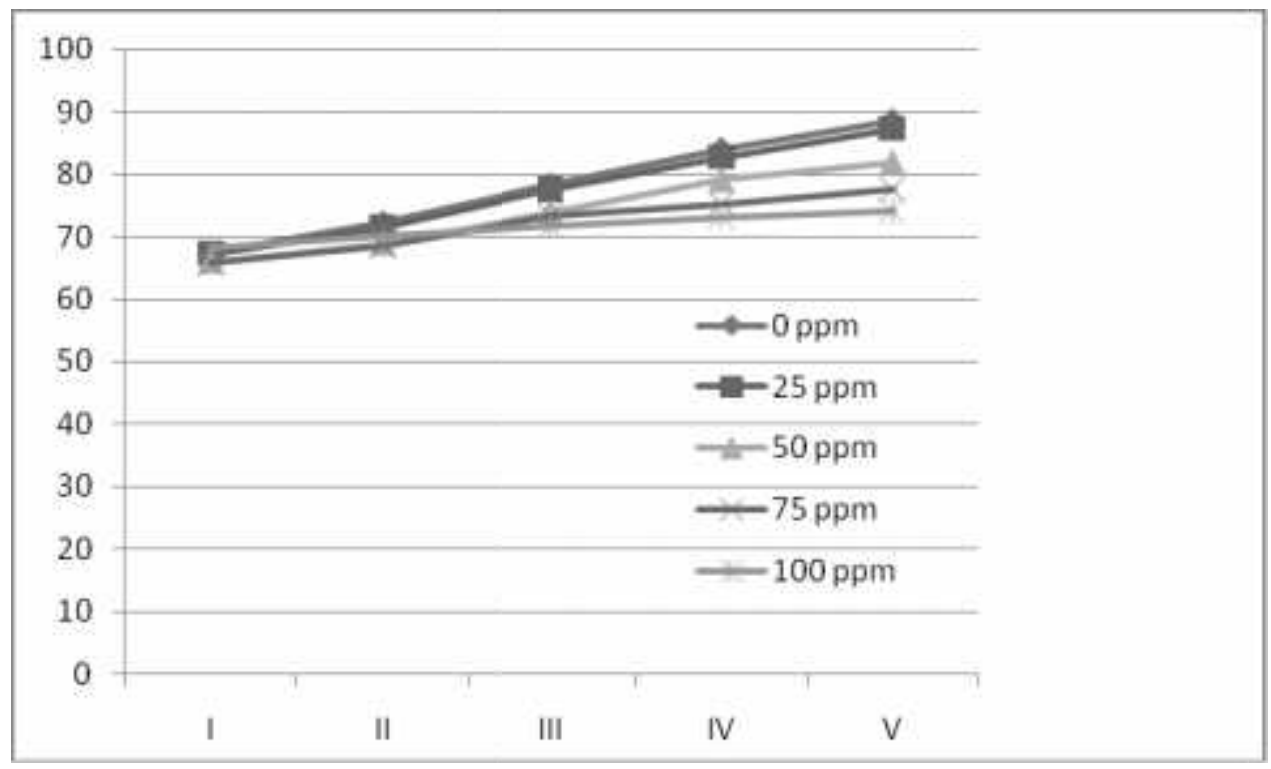

Gambar 1. Pengaruh konsentrasi paclobutrazol (ppm) terhadap pertumbuhan tinggi bibit cengkeh $(\mathrm{cm})$ pada pengamatan ke satu sampai ke lima

(Figure 1. Effect of paclobutrazol concentration (ppm) on the growth of clove seedlings height $(\mathrm{cm})$ on the observation from one to five)

\section{Pembahasan}

Pertumbuhan tinggi tanaman dihasilkan oleh pembelahan dan pemanjangan sel-sel meristem apikal. Sel-sel yang dihasilkan dalam proses pembelahan sel akan membesar dan memanjang sampai ukuran tertentu dan setelah itu pertumbuhan sel akan terhenti. Sel tidak membesar dan memanjang lagi. Pertumbuhan memanjang sel diatur/distimulasi oleh zat pengatur tumbuh (growth regulator) gibberellin (Chaney, 2004). Sehingga kekurangan gibberellin akan mengakibatkan pertumbuhan yang kerdil (dwarfism) (Moore, 1979).

Hasil penelitian ini menunjukkan bahwa zat penghambat tumbuh (growth retardant) paclobutrazol dapat menekan pertumbuhan tinggi bibit cengkeh. Bibit cengkeh yang disemprot dengan zat penghambat tumbuh tersebut lebih pendek dibandingkan dengan bibit yang tidak disemprot (kontrol). Tinggi bibit cengkeh yang disemprot dengan $\mathrm{Pbz}$ berkisar dari terendah, yaitu $73,23 \mathrm{~cm}$ (100 ppm) sampai tertinggi, yaitu 82,80 $\mathrm{cm}(25 \mathrm{ppm})$. Sedangkan tinggi bibit kontrol adalah $84,03 \mathrm{~cm}$. Selanjutnya, berdasarkan uji beda ratarata ternyata antara perlakuan 75 ppm dan 100 ppm tidak berbeda, tetapi berbeda nyata dengan perlakuan lainnya, sehingga kedua perlakuan tersebut disimpulkan sebagai konsentrasi paclobutrazol yang dapat digunakan untuk menghambat pertumbuhan tinggi bibit cengkeh.

Pengaruh paclobutrazol terhadap pertumbuhan tinggi bibit cengkeh dapat dilihat pada Gambar 1. Makin tinggi konsentrasi paclobutrazol (sampai dengan 100 ppm), makin pendek tinggi bibit cengkeh.

Tinggi bibit cengkeh yang disemprot dengan paclobutrazol lebih pendek dibandingkan dengan kontrol, diakibatkan rata-rata panjang ruas bibit yang disemprot dengan zat penghambat tumbuh tersebut lebih pendek dibandingkan dengan kontrol. Rata-rata panjang ruas kontrol sebesar $5,29 \mathrm{~cm}$, sedangkan rata-rata panjang ruas bibit cengkeh yang disemprot dengan paclobutrazol berkisar dari terendah $1,41 \mathrm{~cm}(100 \mathrm{ppm})$ sampai tertinggi $5,08 \mathrm{~cm}$ (25 ppm) (Tabel 1).

Penekanan paclobutrazol terhadap pertambahan tinggi bibit cengkeh, disebabkan oleh ruas-ruas (internodes) yang dihasilkan bibit cengkeh yang disemprot dengan paclobutrazol lebih pendek dibandingkan dengan kontrol. Penekanan paclobutrazol terhadap pertumbuhan tinggi bibit cengkeh tersebut karena zat penghambat tumbuh ini memblok sintesis gibberellin dalam lintasan terpenoid, yaitu dari entkaurene menjadi ent-kaurenol, dan dari ent- 
kaurenol menjadi ent-kaurenal. Bila sintesis gibberellin dihambat maka sel-sel tetap membelah tetapi sel-sel baru tersebut tidak memanjang. Hasilnya adalah pengurangan pertumbuhan tajuk (growth reduction), yaitu tajuk dengan jumlah daun yang sama tapi dengan panjang ruas yang lebih pendek (Chaney, 2003; 2004).

Pengurangan/penekanan pertumbuhan tinggi tanaman akibat pengaruh paclobutrazol berkisar dari rendah $(10 \%)$ sampai yang tinggi (90\%) dengan rata-rata $40-60 \%$ (Chaney, 2003; 2004). Bai et. al. (2004) menemukan reduksi pertumbuhan tajuk tanaman sweetgum sebesar 96\%, dan sebesar $42 \%$ pada Cherrybark oak. Pengurangan tinggi tanaman pada tanaman Gladiolus tristis berkisar $69 \%$ - $92 \%$ (Milandri, Laubscher and Ndakidemi, 2008). Pada penelitian ini ditemukan bahwa pengurangan pertumbuhan tinggi tunas apikal akibat $\mathrm{Pbz}$ adalah berkisar dari terendah, yaitu 3,79 \% (25 ppm) sampai dengan tertinggi, yaitu $69,85 \%$ (100 ppm).

\section{KESIMPULAN}

Paclobutrazol (Pbz) mempengaruhi pertumbuhan tinggi bibit cengkeh (Eugenia aromaticum L.). Makin tinggi konsentrasi aplikasi $\mathrm{Pbz}$, makin pendek bibit cengkeh yang dihasilkan. Penekanan/penghambatan paclobutrazol terhadap pertumbuhan tinggi bibit cengkeh bervariasi dari terendah, yaitu $3,79 \%$ (25 ppm) sampai dengan tertinggi, yaitu 69,85\% (100 ppm).

Penekanan paclobutrazol terhadap pertumbuhan tinggi bibit cengkeh disebabkan ruas tunas apikal tanaman yang disemprot lebih pendek dibandingkan dengan kontrol. Rata-rata panjang ruas tunas apikal tanaman kontrol sebesar $5,29 \mathrm{~cm}$, sedangkan rata-rata panjang ruas tunas apikal bibit cengkeh yang disemprot dengan paclobutrazol berkisar dari terendah $1,41 \mathrm{~cm}$ (100 ppm) sampai tertinggi $5,08 \mathrm{~cm}(25 \mathrm{ppm})$.

Berdasarkan perbandingan pertambahan tinggi tanaman yang disemprot dengan paclobutrazol, maka dosis aplikasi yang dapat digunakan untuk mendapatkan bibit cengkeh yang kerdil adalah konsentrasi 50 sampai dengan 100 ppm.

\section{UCAPAN TERIMA KASIH}

Penelitian ini dibiayai oleh PT. Hanjaya Mandala Sampoerna Tbk. Nomor kontrak: 0067/PMI/PROC/03/2009.

\section{DAFTAR PUSTAKA}

Bai, S., W. Chaney, and Y. Qi. 2004. Response of cambial and shoot growth in trees treated with paclobutrazol. Journal of Arboriculture 30(3): $137-144$.

Christov, Ch., I. Tsvetkov, and V. Kovachev. 1995. Use of paclobutrazol control vegetative growth and improve fruiting efficiency of grapevines (Vitis vinifera L.). BULG. J. PLANT PHYSIOL., 21(4), 64-71.

Carvajal, E., A. Alvarado, F. Sterling, and J. Rodríguez .1998. The Use of Paclobutrazol in Oil Palm Clones During the Nursery Stage. ASD Oil Palm Papers No. 18, 29-33.

Chaney, W. R. 2003. Tree growth retardants: arborists discovering new uses for an old tool. Tree Care Industry, March. 2003.

Chaney, W. R. 2004. Paclobutrazol: More than just a growth retardant. Presented at Pro-Hort Conference, Peoria, Illinois, February $4^{\text {th }}$, 2004.

Guzman, C. C. and J. S. Siemonsma (editors). 1999. Spices. Plant Resources of SouthEast Asia. No. 13. Prosea. Bogor Indonesia.

Meilan, R. 1997. Floral induction in woody angiosperms. New Forests 14: 179 - 202. Kluwer academic publisher. Printed in Netherland.

Mamarimbing, R. 2002a. Respons pertumbuhan dan hasil padi gogo (Oryza sativa

L.) terhadap pemberian paclobutrazol dan pupuk nitrogen. Eugenia 9 (3) : 169 - 173.

Mamarimbing, R. 2002b. Hasil padi gogo (Oryza sativa L.) var. Kalimutu pada beberapa konsentrasi paclobutrazol. Eugenia 9 (4) : $265-268$. 
More Th. C. 1979. Biochemistry and Physiology of Plant Hormones. Springer-Verlag. New York. Inc.

Milandri, S. G., C. P. Laubscher, and P. A. Ndakidemi. 2008. Hydroponic culture of Gladiolus tristis: Application of paclobutrazol for flowering and height control. African Journal of Biotechnology 7 (3) : 239 - 243.

Weaver, R. J. 1972. Plant growth substances in Agriculture. W. H. Freeman and company. San Fransisco. 594pp. 
